Journal of Mathematics and Statistics 5 (3):141-145, 2009

ISSN 1549-3644

(C) 2009 Science Publications

\title{
Sufficient Conditions for Subordination of Meromorphic Functions
}

\author{
Rabha W. Ibrahim and Maslina Darus \\ School of Mathematical Sciences, Faculty of Science and Technology, \\ University Kebangsaan Malaysia, Bangi 43600 Selangor D. Ehsan, Malaysia
}

\begin{abstract}
Problem statement: The problem of giving sufficient condition for certain class of meromorphic functions defined as differential operator was studied. Approach: The differential operator of meromorphic functions containing fractional power was proposed and defined. The preliminary concept of subordination was introduced to give sharp proofs for certain sufficient conditions of the differential operator aforementioned. Results: Having new operator, subordination theorems established by using standard concept of subordination and reduced to well-known results studied by various researchers. The operator was then applied for fractional calculus and obtained new subordination theorem. Conclusion: Therefore, by having new operators, new criteria and new set of subordination theorems could be obtained with some earlier results and standard methods.
\end{abstract}

Key words: Fractional calculus; Subordination; meromorphic function

\section{INTRODUCTION}

The study of meromorphic functions has been the major interests for many authors in the field of univalent functions. Recently, various differential operators have been introduced for certain class of analytic univalent functions in the unit disk. In this article, we follow the similar approach by introducing a differential operator of meromorphic functions in the punctured disk. We begin by giving some well-known notations and preliminary results on the class of meromorphic functions and also the basic knowledge of subordination. Later we derive the differential operator aforementioned. Once the differential operator being derived, we shall discuss on the conditions for subordination.

Now, let $\varepsilon_{\alpha}^{+}$be the class of functions $\mathrm{F}(\mathrm{z})$ of the form:

$$
\mathrm{F}(\mathrm{z})=\frac{1}{\mathrm{z}}+\sum_{\mathrm{n}=0}^{\infty} \mathrm{a}_{\mathrm{n}} \mathrm{z}^{\mathrm{n}+\alpha-1}, \alpha \geq 1
$$

Which are analytic in the punctured unit disk $\mathrm{U}:=\{\mathrm{z} \in \mathbb{C}, 0>|\mathrm{z}|>1\}$ And let $\varepsilon_{\alpha}^{-}$be the class of functions of the form:

$$
\mathrm{F}(\mathrm{z})=\frac{1}{\mathrm{z}}-\sum_{\mathrm{n}=0}^{\infty} \mathrm{a}_{\mathrm{n}} \mathrm{z}^{\mathrm{n}+\alpha-1}, \alpha \geq 1
$$

Which are analytic in the punctured unit disk U. Let us recall the principle of subordination between analytic functions: let the functions $\mathrm{f}$ and $\mathrm{g}$ be analytic in $\Delta:=\{z \in \mathbb{C},|z|<1\}$, then we say that the function $\mathrm{f}$ is subordinate to $\mathrm{g}$ if there exists a Schwarz function W(z) analytic in $\Delta$ such that:

$$
f(z)=g(w(z)), z \in \Delta
$$

We denote this subordination by:

$$
\mathrm{f} \prec \mathrm{g} \text { or } \mathrm{f}(\mathrm{z}) \prec \mathrm{g}(\mathrm{z}), \mathrm{z} \in \Delta
$$

If the function $\mathrm{g}$ is univalent in $\Delta$ the above subordination is equivalent to:

$$
\mathrm{f}(0)=\mathrm{g}(0) \text { and } \mathrm{f}(\Delta) \subset \mathrm{g}(\Delta)
$$

Let $\varphi: \mathbb{C}^{3} \times \Delta \rightarrow \mathbb{C}$ and let $\mathrm{h}$ be univalent in $\Delta$ Assume that $\mathrm{p}, \varphi$ are analytic and univalent in $\Delta$ if $\mathrm{p}$ satisfies the differential superordination:

$$
\left.\mathrm{h}(\mathrm{z}) \prec \varphi(\mathrm{p}(\mathrm{z})), \mathrm{zp}^{\prime}(\mathrm{z}), \mathrm{z}^{2} \mathrm{p}^{\prime \prime}(\mathrm{z}) ; \mathrm{z}\right)
$$

Then $\mathrm{p}$ is called a solution of the differential superordination. (If $\mathrm{f}$ is subordinate to $\mathrm{g}$, then $\mathrm{g}$ is called to be superordinate to $f$.) An analytic function $q$ is called a subordinant if $q \prec p$ for all $p$ satisfying (1). An

Corresponding Author: Maslina Darus, Faculty of Science and Technology, School of Mathematical Sciences, University Kebangsaan Malaysia, Bangi 43600 Selangor D. Ehsan, Malaysia 
univalent function $\mathrm{q}$ such that $\mathrm{p} \prec \mathrm{q}$ for all subordinants p of (1) is said to be the best subordinant.

Let $\varepsilon^{+}$be the class of analytic functions, in $U$ of the form $f(z)=\frac{1}{z}+\sum_{n=0}^{\infty} a_{n} z^{n}$ and let $\varepsilon^{-}$be the class of analytic functions, in $\mathrm{U}$ of the form:

$$
f(z)=\frac{1}{z}-\sum_{n=0}^{\infty} a_{n} z^{n}, a_{n} \geq 0, n=0,1, \ldots
$$

A function $f(z) \in \varepsilon^{+}$is meromorphic starlike if $f(z) \neq 0$ and:

$$
-\mathfrak{R}\left\{\frac{\mathrm{zf}(\mathrm{z})}{\mathrm{f}(\mathrm{z})}\right\}>0, \mathrm{z} \in \mathrm{U}
$$

Similarly, the function $f(z)$ is meromorphic convex if $\mathrm{f}^{\prime}(\mathrm{z}) \neq 0$ and:

$$
-\Re\left\{1+\frac{\mathrm{zf}^{\prime \prime}(\mathrm{z})}{\mathrm{f}^{\prime}(\mathrm{z})}\right\}>0, \mathrm{z} \in \mathrm{U}
$$

Ravichandran et al. ${ }^{[1]}$ studied sufficient conditions for subordination for class $\left(\varepsilon^{+}\right)$of meromorphic functions:

$$
-\frac{z f^{\prime}(z)}{f(z)} \prec q(z), z \in U
$$

A function $\mathrm{F}(\mathrm{z}) \in \varepsilon_{\alpha}^{+}\left(\varepsilon_{\alpha}^{-}\right)$such that $\mathrm{F}(\mathrm{z}) \neq 0$ is called meromorphic starlike if:

$$
-\mathfrak{R}\left\{\frac{\mathrm{zF}(\mathrm{z})}{\mathrm{F}(\mathrm{z})}\right\}>0, \mathrm{z} \in \mathrm{U}
$$

And the function $\mathrm{F}(\mathrm{z})$ is meromorphic convex if $\mathrm{F}^{\prime}(\mathrm{z}) \neq 0$ and:

$$
-\Re\left\{1+\frac{z F^{\prime \prime}(z)}{F^{\prime}(z)}\right\}>0, z \in U
$$

\section{MATERIALS AND METHODS}

We define a differential operator as follows. Let $\mathrm{F} \in \varepsilon_{\alpha}^{+}$, then:

$$
\begin{aligned}
& \mathrm{D}_{\alpha, \lambda}^{0} \mathrm{~F}(\mathrm{z})=\mathrm{F}(\mathrm{z})=\frac{1}{\mathrm{z}}+\sum_{\mathrm{n}=0}^{\infty} \mathrm{a}_{\mathrm{n}} \mathrm{z}^{\mathrm{n}+\alpha-1} \\
& \mathrm{D}_{\alpha, \lambda}^{1} \mathrm{~F}(\mathrm{z})=(2 \alpha-\lambda+1) \mathrm{F}(\mathrm{z})+ \\
& (2 \alpha-\lambda) \mathrm{zF}^{\prime}(\mathrm{z}) \\
& =\frac{1}{\mathrm{z}}+\sum_{\mathrm{n}=0}^{\infty}[(2 \alpha-\lambda)(\mathrm{n}+\alpha)+1] \mathrm{a}_{\mathrm{n}} \mathrm{z}^{\mathrm{n}+\alpha-1} \\
& \vdots \\
& \mathrm{D}_{\alpha, \lambda}^{\mathrm{k}} \mathrm{F}(\mathrm{z})=\mathrm{D}\left(\mathrm{D}^{\mathrm{k}-1} \mathrm{~F}(\mathrm{z})\right) \\
& =\frac{1}{\mathrm{z}}+\sum_{\mathrm{n}=0}^{\infty}[(2 \alpha-\lambda)(\mathrm{n}+\alpha)+1]^{\mathrm{k}} \mathrm{a}_{\mathrm{n}} \mathrm{z}^{\mathrm{n}+\alpha-1}
\end{aligned}
$$

We will establish some sufficient conditions for functions $F \in \varepsilon_{\alpha}^{+}$and $F \in \varepsilon_{\alpha}^{-}$to satisfy:

$$
-\frac{z\left[D_{\alpha, \lambda}^{k} F(z)\right]^{\prime}}{D_{\alpha, \lambda}^{k} F(z)} \prec q(z), z \in U, n=1,2, \ldots
$$

where, $F(z) \neq 0, q(z)$ is a given univalent function in $U$. Moreover, we will give applications for this result in fractional calculus. We shall need the following known results.

Lemma 1: Shanmugam et al. ${ }^{[2]}$ Let $\mathrm{q}(\mathrm{z})$ be convex univalent in the unit disk $\Delta$ and $\psi$ and $\gamma \in \mathbb{C}$ with $\Re\left\{1+\frac{\mathrm{zq}^{\prime \prime}(\mathrm{z})}{\mathrm{q}^{\prime}(\mathrm{z})}+\frac{\psi}{\gamma}\right\}>0 \quad$ If $\mathrm{p}(\mathrm{z}) \quad$ is analytic in $\Delta$ and: $\psi \mathrm{p}(\mathrm{z})+\gamma \mathrm{zp}(\mathrm{z}) \prec \psi \mathrm{q}(\mathrm{z})+\gamma \mathrm{zq}(\mathrm{z})$ then $\mathrm{p}(\mathrm{z}) \prec \mathrm{q}(\mathrm{z})$ and $\mathrm{q}$ is the best dominant.

Lemma 2: Let $\mathrm{q}(\mathrm{z})$ be univalent in the unit disk $\Delta$ and $\theta$ and $\phi$ be analytic in a domain D containing $\mathrm{q}(\Delta)$ with $\varphi(\mathrm{w}) \neq 0$ when $\mathrm{w} \in \mathrm{q}(\Delta) \mathrm{Set}^{[3]}$ :

$$
\mathrm{Q}(\mathrm{z}):=\mathrm{zq}(\mathrm{z}) \varphi(\mathrm{q}(\mathrm{z})), \mathrm{h}(\mathrm{z}):=\theta(\mathrm{q}(\mathrm{z}))+\mathrm{Q}(\mathrm{z})
$$

Suppose that:

- $\quad \mathrm{Q}(\mathrm{z})$ is starlike univalent in $\Delta$ and

- $\quad \mathfrak{R} \frac{\mathrm{zh}^{\prime}(\mathrm{z})}{\mathrm{Q}(\mathrm{z})}>0$ for $\mathrm{z} \in \Delta$

If:

$$
\theta(\mathrm{p}(\mathrm{z}))+\mathrm{zp}^{\prime}(\mathrm{z}) \varphi(\mathrm{p}(\mathrm{z})) \prec \theta(\mathrm{q}(\mathrm{z}))+\mathrm{zq}(\mathrm{z}) \varphi(\mathrm{q}(\mathrm{z}))
$$

Then $\mathrm{p}(\mathrm{z}) \prec \mathrm{q}(\mathrm{z})$ and $\mathrm{q}(\mathrm{z})$ is the best dominant. 


\section{RESULTS}

Now we establish some sufficient conditions for subordination of analytic functions in the classes $\varepsilon_{\alpha}^{+}$ and $\varepsilon_{\alpha}^{-}$.

Theorem 1: Let the function $\mathrm{q}(\mathrm{z})$ be convex univalent in $U$ such that $\mathrm{q}^{\prime}(\mathrm{z}) \neq 0$ and:

$\mathfrak{R}\left\{1+\frac{\mathrm{zq} \mathrm{q}^{\prime \prime}(\mathrm{z})}{\mathrm{q}^{\prime}(\mathrm{z})}+\frac{\Psi}{\gamma}\right\}>0, \gamma \neq 0$

Suppose that $-\frac{z\left[D_{\alpha, \lambda}^{k} F(z)\right]^{\prime}}{D_{\alpha, \lambda}^{k} F(z)}$ is analytic in U If $F \in \varepsilon_{\alpha}^{+}$ satisfies the subordination:

$$
\begin{aligned}
& -\frac{z\left[D_{\alpha, \lambda}^{k} F(z)\right]^{\prime}}{D_{\alpha, \lambda}^{k} F(z)}\left\{\psi+\gamma\left[1+\frac{z\left[D_{\alpha, \lambda}^{k} F(z)\right]^{\prime \prime}}{\left[D_{\alpha, \lambda}^{k} F(z)\right]^{\prime}}-\frac{z\left[D_{\alpha, \lambda}^{k} F(z)\right]^{\prime}}{D_{\alpha, \lambda}^{k} \mathrm{~F}(z)}\right]\right\} \\
& \prec \psi q(z)+\gamma z q^{\prime}(z)
\end{aligned}
$$

Then:

$$
-\frac{z\left[D_{\alpha, \lambda}^{k} F(z)\right]^{\prime}}{D_{\alpha, \lambda}^{k} F(z)} \prec q(z), z \in U
$$

and $\mathrm{q}(\mathrm{z})$ is the best dominant.

Proof: Let the function $\mathrm{p}(\mathrm{z})$ be defined by:

$$
\mathrm{p}(\mathrm{z}):=-\frac{\mathrm{z}\left[\mathrm{D}_{\alpha, \lambda}^{\mathrm{k}} \mathrm{F}(\mathrm{z})\right]^{\prime}}{\mathrm{D}_{\alpha, \lambda}^{\mathrm{k}} \mathrm{F}(\mathrm{z})}, \mathrm{z} \in \mathrm{U}
$$

it can easily be observed that:

$$
\begin{aligned}
& \psi p(z)+\gamma z p^{\prime}(z)=-\frac{z\left[D_{\alpha, \lambda}^{k} F(z)\right]^{\prime}}{D_{\alpha, \lambda}^{k} F(z)} \\
& \left\{\psi+\gamma\left[1+\frac{z\left[D_{\alpha, \lambda}^{k} F(z)\right]^{\prime \prime}}{\left[D_{\alpha, \lambda}^{k} F(z)\right]^{\prime}}-\frac{z\left[D_{\alpha, \lambda}^{k} F(z)\right]^{\prime}}{D_{\alpha, \lambda}^{k} F(z)}\right]\right\} \\
& \prec \psi q(z)+\gamma z q^{\prime}(z)
\end{aligned}
$$

Then by the assumption of the theorem we have that the assertion of the theorem follows by an application of Lemma 1.

When $\mathrm{k}=0$, we obtain the following result:

Corollary 1: Let the function $\mathrm{q}(\mathrm{z})$ be univalent in U. If q satisfies:

$$
-\frac{z F^{\prime}(z)}{F(z)}\left\{\psi+\gamma\left[1+\frac{z^{\prime \prime}(z)}{F^{\prime}(z)}-\frac{z F^{\prime}(z)}{F(z)}\right]\right\} \prec \psi q(z)+\gamma z q^{\prime}(z)
$$

Then:

$$
-\frac{\mathrm{zF}(\mathrm{z})}{\mathrm{F}(\mathrm{z})} \prec \mathrm{q}(\mathrm{z}), \mathrm{z} \in \mathrm{U}
$$

and $\mathrm{q}(\mathrm{z})$ is the best dominant.

Theorem 2: Let the function $q(z)$ be univalent in $U$ such that $\mathrm{q}(\mathrm{z}) \neq 0, \mathrm{z} \in \mathrm{U}, \frac{\mathrm{zq}(\mathrm{z})}{\mathrm{q}(\mathrm{z})}$ is starlike univalent in $\mathrm{U}$ and:

$$
\mathfrak{R}\left\{\frac{\mathrm{a}}{\mathrm{b}} \mathrm{q}(\mathrm{z})+\left[1+\frac{\mathrm{zq} \mathrm{q}^{\prime \prime}(\mathrm{z})}{\mathrm{q}^{\prime}(\mathrm{z})}-\frac{\mathrm{zq}(\mathrm{z})}{\mathrm{q}(\mathrm{z})}\right]\right\}>0, \mathrm{~b} \neq 0, \mathrm{q}^{\prime}(\mathrm{z}) \neq 0, \mathrm{z} \in \mathrm{U}
$$

If $F \in \varepsilon_{\alpha}^{-}$satisfies the subordination:

$$
\begin{aligned}
& \mathrm{a}\left[-\frac{\mathrm{z}\left[\mathrm{D}_{\alpha, \lambda}^{\mathrm{k}} \mathrm{F}(\mathrm{z})\right]^{\prime}}{\mathrm{D}_{\alpha, \lambda}^{\mathrm{k}} \mathrm{F}(\mathrm{z})}\right]+\mathrm{b}\left[1+\frac{\mathrm{z}\left[\mathrm{D}_{\alpha, \lambda}^{\mathrm{k}} \mathrm{F}(\mathrm{z})\right]^{\prime \prime}}{\left[\mathrm{D}_{\alpha, \lambda}^{\mathrm{k}} \mathrm{F}(\mathrm{z})\right]^{\prime}}-\frac{\mathrm{z}\left[\mathrm{D}_{\alpha, \lambda}^{\mathrm{k}} \mathrm{F}(\mathrm{z})\right]^{\prime}}{\mathrm{D}_{\alpha, \lambda}^{\mathrm{k}} \mathrm{F}(\mathrm{z})}\right] \\
& \prec \mathrm{aq}(\mathrm{z})+\mathrm{b} \frac{\mathrm{zq}(\mathrm{z})}{\mathrm{q}(\mathrm{z})}
\end{aligned}
$$

Then:

$$
-\frac{\mathrm{z}\left[\mathrm{D}_{\alpha, \lambda}^{\mathrm{k}} \mathrm{F}(\mathrm{z})\right]^{\prime}}{\mathrm{D}_{\alpha, \lambda}^{\mathrm{k}} \mathrm{F}(\mathrm{z})} \prec \mathrm{q}(\mathrm{z})
$$

and $\mathrm{q}(\mathrm{z})$ is the best dominant.

Proof: Let the function $\mathrm{p}(\mathrm{z})$ be defined by:

$\mathrm{p}(\mathrm{z}):=-\frac{\mathrm{z}\left[\mathrm{D}_{\alpha, \lambda}^{\mathrm{k}} \mathrm{F}(\mathrm{z})\right]^{\prime}}{\mathrm{D}_{\alpha, \lambda}^{\mathrm{k}} \mathrm{F}(\mathrm{z})}, \mathrm{z} \in \mathrm{U}$

By setting:

$\theta(\omega):=\mathrm{a} \omega$ and $\varphi(\omega):=\frac{\mathrm{b}}{\omega}, \mathrm{b} \neq 0$

It can easily observed that $\theta(\omega)$ is analytic in $\mathbb{C}, \varphi(\omega)$ is analytic in $\mathbb{C} \backslash\{0\}$ and that $\varphi(\omega) \neq 0, \omega \in \mathbb{C} \backslash\{0\}$ Also we obtain:

$$
\begin{aligned}
\mathrm{Q}(\mathrm{z}) & =\mathrm{zq}(\mathrm{z}) \varphi(\mathrm{q}(\mathrm{z}))=\mathrm{b} \frac{\mathrm{zq^{ \prime }}(\mathrm{z})}{\mathrm{q}(\mathrm{z})} \text { and } \mathrm{h}(\mathrm{z})=\theta(\mathrm{q}(\mathrm{z}))+\mathrm{Q}(\mathrm{z}) \\
& =\mathrm{aq}(\mathrm{z})+\mathrm{b} \frac{\mathrm{zq}(\mathrm{z})}{\mathrm{q}(\mathrm{z})}
\end{aligned}
$$


It is clear that $\mathrm{Q}(\mathrm{z})$ is starlike univalent in $\mathrm{U}$ :

$\mathfrak{R}\left\{\frac{\mathrm{zh}^{\prime}(\mathrm{z})}{\mathrm{Q}(\mathrm{z})}\right\}=\mathfrak{R}\left\{\frac{\mathrm{a}}{\mathrm{b}} \mathrm{q}(\mathrm{z})+\left[1+\frac{\mathrm{zq}^{\prime \prime}(\mathrm{z})}{\mathrm{q}^{\prime}(\mathrm{z})}-\frac{\mathrm{zq}^{\prime}(\mathrm{z})}{\mathrm{q}(\mathrm{z})}\right]\right\}>0$

Straightforward computation, we have:

$$
\begin{aligned}
\mathrm{ap}(\mathrm{z})=\mathrm{b} \frac{\mathrm{zp}(\mathrm{z})}{\mathrm{p}(\mathrm{z})}= & \mathrm{a}\left[-\frac{\mathrm{z}\left[\mathrm{D}_{\alpha, \lambda}^{\mathrm{k}} \mathrm{F}(\mathrm{z})\right]^{\prime}}{\mathrm{D}_{\alpha, \lambda}^{\mathrm{k}} \mathrm{F}(\mathrm{z})}\right]+\mathrm{b}\left[1+\frac{\mathrm{z}\left[\mathrm{D}_{\alpha, \lambda}^{\mathrm{k}} \mathrm{F}(\mathrm{z})\right]^{\prime \prime}}{\left[\mathrm{D}_{\alpha, \lambda}^{\mathrm{k}} \mathrm{F}(\mathrm{z})\right]^{\prime}}\right. \\
& \left.-\frac{\mathrm{z}\left[\mathrm{D}_{\alpha, \lambda}^{\mathrm{k}} \mathrm{F}(\mathrm{z})\right]^{\prime}}{\left[\mathrm{D}_{\alpha, \lambda}^{\mathrm{k}} \mathrm{F}(\mathrm{z})\right.}\right] \prec \mathrm{aq}(\mathrm{z})+\mathrm{b} \frac{\mathrm{zq^{ \prime }}(\mathrm{z})}{\mathrm{q}(\mathrm{z})}
\end{aligned}
$$

Then by the assumption of the theorem we have that the assertion of the theorem follows by an application of Lemma 2.

When $\mathrm{k}=0$ we obtain the following result:

Corollary 2: Let the function $\mathrm{q}(\mathrm{z})$ be univalent in U. If q satisfies:

$$
(a+b)\left[-\frac{z F^{\prime}(z)}{F(z)}\right]+b\left[1+\frac{z F^{\prime \prime}(z)}{F^{\prime}(z)}\right] \prec a q(z)+b \frac{z q^{\prime}(z)}{q(z)}
$$

Then:

$$
-\frac{z F^{\prime}(z)}{F(z)} \prec q(z), z \in U
$$

and $\mathrm{q}(\mathrm{z})$ is the best dominant.

\section{DISCUSSION}

Results obtained in Theorem 1 and 2. can be applied for the fractional integral operators. Assume that:

$$
\mathrm{f}(\mathrm{z})=\sum_{\mathrm{n}=0}^{\infty} \phi_{\mathrm{n}} \mathrm{z}^{\mathrm{n}}
$$

And let us begin with the following definitions:

Definition 1: The fractional integral of order $\alpha$ is defined, for a function $\mathrm{f}(\mathrm{z})$ by $^{[4]}$ :

$$
\mathrm{I}_{\mathrm{z}}^{\alpha} \mathrm{f}(\mathrm{z}):=\frac{1}{\Gamma(\alpha)} \int_{0}^{\mathrm{z}} \mathrm{f}(\zeta)(\mathrm{z}-\zeta)^{\alpha-1} \mathrm{~d} \zeta ; 0 \leq \alpha<1
$$

where, the function $\mathrm{f}(\mathrm{z})$ is analytic in simply-connected region of the complex z-plane $(\mathbb{C})$ containing the origin and the multiplicity of $(\mathrm{z}-\zeta)^{\alpha-1}$ is removed by requiring $\log (\mathrm{z}-\zeta)$ to be real when $(\mathrm{z}-\zeta)>0$ Note that $I_{z}^{\alpha} f(z)=f(z) \times \frac{z^{\alpha-1}}{\Gamma(\alpha)}$ for $z>0$ and 0 for $z \leq 0^{[5]}$. For more properties ${ }^{[6]}$.

From Definition 1, we have:

$$
I_{z}^{\alpha} f(z)=f(z) \times \frac{z^{\alpha-1}}{\Gamma(\alpha)}=\frac{z^{\alpha-1}}{\Gamma(\alpha)} \sum_{n=0}^{\infty} \phi_{n} z^{n}=\sum_{n=0}^{\infty} a_{n} z^{n+\alpha-1}
$$

where, $\mathrm{a}_{\mathrm{n}}:=\frac{\varphi_{\mathrm{n}}}{\Gamma(\alpha)}$, for all $\mathrm{n}=2,3, \ldots$.

Thus:

$$
\frac{1}{\mathrm{z}}+\mathrm{I}_{\mathrm{z}}^{\alpha} \mathrm{f}(\mathrm{z}) \in \varepsilon_{\alpha}^{+} \text {and } \frac{1}{\mathrm{z}}-\mathrm{I}_{\mathrm{z}}^{\alpha} \mathrm{f}(\mathrm{z}) \in \varepsilon_{\alpha}^{-}\left(\phi_{\mathrm{n}} \geq 0\right)
$$

Then we have the following results:

Theorem 3: Let the assumptions of Corollary 1. hold, then:

$$
-\frac{\mathrm{z}\left(\frac{1}{\mathrm{Z}}+\mathrm{I}_{\mathrm{z}}^{\alpha} \mathrm{f}(\mathrm{z})\right)^{\prime}}{\frac{1}{\mathrm{z}}+\mathrm{I}_{\mathrm{z}}^{\alpha} \mathrm{f}(\mathrm{z})} \prec \mathrm{q}(\mathrm{z}), \mathrm{z} \in \mathrm{U}
$$

and $\mathrm{q}(\mathrm{z})$ is the best dominant.

Proof. Let the function $\mathrm{F}(\mathrm{z})$ be defined by:

$$
F(z):=\frac{1}{z}+I_{z}^{\alpha} f(z), \quad z \in U
$$

Theorem 4: Let the assumptions of Corollary 2. hold, then:

$$
-\frac{\mathrm{z}\left(\frac{1}{\mathrm{z}}-\mathrm{I}_{\mathrm{z}}^{\alpha} \mathrm{f}(\mathrm{z})\right)^{\prime}}{\frac{1}{\mathrm{z}}-\mathrm{I}_{\mathrm{z}}^{\alpha} \mathrm{f}(\mathrm{z})} \prec \mathrm{q}(\mathrm{z}), \mathrm{z} \in \mathrm{U}
$$

and $\mathrm{q}(\mathrm{z})$ is the best dominant.

Proof: Let the function $F(z)$ be defined by:

$$
\mathrm{F}(\mathrm{z}):=\frac{1}{\mathrm{z}}-\mathrm{I}_{\mathrm{z}}^{\alpha} \mathrm{f}(\mathrm{z}), \mathrm{z} \in \mathrm{U}
$$

\section{CONCLUSION}

The operator defined was motivated by various work studied earlier by the researchers ${ }^{[7-9]}$. This 
operator can be generalised further and many other results such as the coefficient estimates and distortion theorem can be obtained.

\section{ACKNOWLEDGEMENT}

The study here is fully supported by EScienceFund grant: 04-01-02-SF0425, MOSTI, Malaysia.

\section{REFERENCES}

1. Ravichandran, V., S.K. Sivaprasad and M. Darus, 2004. On a subordination theorem for a class of meromorphic functions. J. Ineq. Pure Applied Math., 5: 8-8.

http://www.emis.de/journals//JIPAM/article360.ht $\mathrm{ml} . \mathrm{sid} ?=360$

2. Shanmugam, T.N., V. Ravichandran and S. Sivasubramanian, 2006. Differential sandwich theorems for some subclasses of analytic functions, Austral. J. Math. Anal. Applied, 3: 1-11. http://ajmaa.org/cgi-

bin/paper.pl?string=v3n1/V3I1P8.tex

3. Miller, S.S. and P.T. Mocanu, 2000. Differential Subordinantions: Theory and Applications. Pure and Applied Mathematics No.225 Dekker, New York, ISBN: 0-8247-0029-5.
4. Srivastava, H.M. and S. Owa, 1989. Univalent Functions, Fractional Calculus and Their Applications, Halsted Press, John Wiley and Sons, New York, Chichester, Brisbane and Toronto, ISBN: 10: 0470216301.

5. Miller, K.S. and B. Ross, 1993. An Introduction to The Fractional Calculus and Fractional Differential Equations. 1st Edn., John Wiley and Sons, Inc., ISBN: 0471588849, pp: 384.

6. Ibrahim, R.W. and M. Darus, 2008. Subordination and superordination for univalent solutions for fractional differential equations. J. Math. Anal. Applied, 345: 871-879. DOI: 10.1016/J.JMAA.2008.05.017

7. Ibrahim, R.W. and M. Darus, 2008. On subordination theorems for new classes of normalize analytic functions. Appllied Math. Sci., 2: 2785-2794. http://www.mhikari.com/ams/ams-password-2008/ams-password5356-2008/darusAMS53-56-2008.pdf

8. Darus, M. and R.W. Ibrahim, 2008. Coefficient inequalities for a new class of univalent functions. J. Math., 29: 221-229. http://www.citeulike.org/article/3746585

9. Ibrahim, R.W and M. Darus, 2009. Differential subordination results for new classes of the family $\varepsilon(\Phi, \Psi)$. J. Ineq. Pure Applied Math., 10: 9-9. http://jipam.vu.edu.au/article.php?sid=1064 